\title{
Immunohaemostasis: a new view on haemostasis during sepsis
}

\author{
Xavier Delabranche ${ }^{1,2}$, Julie Helms $s^{1,3}$ and Ferhat Meziani ${ }^{1,2^{*}}$
}

\begin{abstract}
Host infection by a micro-organism triggers systemic inflammation, innate immunity and complement pathways, but also haemostasis activation. The role of thrombin and fibrin generation in host defence is now recognised, and thrombin has become a partner for survival, while it was seen only as one of the "principal suspects" of multiple organ failure and death during septic shock. This review is first focused on pathophysiology. The role of contact activation system, polyphosphates and neutrophil extracellular traps has emerged, offering new potential therapeutic targets. Interestingly, newly recognised host defence peptides (HDPs), derived from thrombin and other "coagulation" factors, are potent inhibitors of bacterial growth. Inhibition of thrombin generation could promote bacterial growth, while HDPs could become novel therapeutic agents against pathogens when resistance to conventional therapies grows. In a second part, we focused on sepsis-induced coagulopathy diagnostic challenge and stratification from "adaptive" haemostasis to "noxious" disseminated intravascular coagulation (DIC) either thrombotic or haemorrhagic. Besides usual coagulation tests, we discussed cellular haemostasis assessment including neutrophil, platelet and endothelial cell activation. Then, we examined therapeutic opportunities to prevent or to reduce "excess" thrombin generation, while preserving "adaptive" haemostasis. The fail of international randomised trials involving anticoagulants during septic shock may modify the hypothesis considering the end of haemostasis as a target to improve survival. On the one hand, patients at low risk of mortality may not be treated to preserve "immunothrombosis" as a defence when, on the other hand, patients at high risk with patent excess thrombin and fibrin generation could benefit from available (antithrombin, soluble thrombomodulin) or ongoing (FXI and FXII inhibitors) therapies. We propose to better assess coagulation response during infection by an improved knowledge of pathophysiology and systematic testing including determination of DIC scores. This is one of the clues to allocate the right treatment for the right patient at the right moment.
\end{abstract}

Keywords: Infection, Septic shock, Disseminated intravascular coagulation (DIC), Host defence peptides (HDPs), Contact phase, Neutrophil extracellular traps (NETs)

\section{Background}

The aim of this review is to describe the battle between a foreign pathogen and the host regarding thrombin generation, one of the key molecules to win or to lose the war for surviving. Thrombin is involved in thrombus formation (via fibrin network), in anticoagulation and fibrinolysis [via thrombomodulin and (activated) protein C], focalisation (via glycosaminoglycans and antithrombin),

\footnotetext{
*Correspondence: ferhat.meziani@chru-strasbourg.fr

${ }^{1}$ Université de Strasbourg, Faculté de Médecine \& Hôpitaux Universitaires de Strasbourg, Service de Réanimation, Nouvel Hôpital Civil, Strasbourg, France

Full list of author information is available at the end of the article
}

but also in vascular permeability and tone (via endothelial cell receptors and kinin pathways) [1-3].

During infection, initiation of thrombin generation may occur through different pathways [35]:

i. Bacteria initiation with endothelial invasion [4] and platelet activation (via Fc $\gamma$ RIIa, $\alpha I I b \beta 3$ and platelet factor 4) [5],

ii. Bacterial polyphosphate (polyP) initiation through the "contact" pathway [6],

iii. Endothelial cell expression of encrypted tissue factor (TF), vascular cell recruitment and activation by thrombin, cytokines and microparticles $[1,7,8]$, 
iv. fibrin network, neutrophil extracellular traps (NETs) and histones $[9,10]$.

Haemostasis should therefore be considered as a nonspecific first line of host defence-at least when localised to a unique endothelial injury-considering the growing role of platelets as immune cells [11-13]. This immune response has been called "immunothrombosis" [14]. In this line, immunohaemostasis process may help to capture pathogens, prevent tissue invasion and concentrate antimicrobial cells and peptides including thrombinderived host defence peptides. Therefore, when regulated, a low-grade activation of thrombin generation may help survive the bacterial challenge [14]. Yet, inhibition of thrombin generation by Dabigatran promotes bacterial growth and spreading with increased mortality in experimental model of Klebsiella pneumoniae-induced murine pneumonia [15].

On the other hand, thrombin can become deleterious if ongoing activation of the coagulation, owing to defective natural anticoagulants, leads to excessive thrombin formation. Combined with defective fibrinolysis, thrombin results in fibrin deposits in microvessels and eventually in disseminated intravascular coagulation (DIC) $[16,17]$. DIC thus represents a deregulation and/or an overwhelmed haemostasis activation response triggered by pathogens and/or host responses during septic shock [14]. DIC could be classified in "asymptomatic", "bleeding" (haemorrhagic), "thrombotic" (organ failure) and ultimately "massive bleeding" (fibrinolytic) type, according to its clinical presentation [18]. Except asymptomatic one, all types are characterised by delayed clotting times (PT and aPTT), low fibrinogen and platelets count owing to their consumption $[19,20]$. Although known for many years, the role of DIC in the pathogenesis of septic shock remains a matter of debate [21-23]. Since then, coagulation was considered as a potential therapeutic target. The recognition of new targets implied in thrombosis-but not in haemostasisopens a new window over innovative therapies.

\section{Physiology of thrombin generation}

For didactic settings, haemostasis can be separated into three phases:

i. Initiation,

ii. Propagation and regulation,

iii. Fibrinolysis.

A brief overview of haemostasis is available in Additional file 1 and Additional file 2: Figure S1 provides the different steps of thrombin generation, fibrin formation and regulation $[1,24]$.

\section{Pathophysiology of thrombin and fibrin formation during infection}

The contact between a prokaryote and a eukaryote can result in symbiosis or infection resulting in host or pathogen survival. To survive infection, the host initiates a complex inflammatory response including innate immunity, complement and coagulation pathways. These two cascades have a unique origin, but many refinements over the past 500 million years improved their specificities $[25,26]$. In this view, coagulation is fundamental to survive and the following section will highlight the role of contact activation system (not involved in "normal" haemostasis), the interplay between pathogens, coagulation and fibrinolysis pathways, and the emerging role of antimicrobial host defence peptides generated by proteolysis of "coagulation" proteins $[17,27,28]$.

\section{Initiation: the emerging role of contact activation system}

(Fig. 1)

\section{Physiology or pathophysiology?}

An old view of haemostasis distinguished two initiation pathways: tissue factor ("extrinsic" pathway) and contact activation system (CAS) ("intrinsic" pathway). The latter requires a "contact" activator, prekallikrein (PK), high molecular weight kininogen (HK), factor XII (FXII) and FXI [29]. A deficit of one of these proteins results in prolonged aPTT although no haemorrhagic diathesis is evidenced in patients. CAS does not seem to be involved in "normal" haemostasis and may be restricted to pathological conditions resulting in negatively charged surfaces, including sepsis (via NETs and polyP), but also acute respiratory distress syndrome (ARDS) [30] and blood contact with artificial surfaces (intravascular catheters, extracorporeal circuits).

"Contact" activator is a negatively charged surface able to link and induce a conformational change in FXII that auto-activates FXII in $\alpha$-FXIIa in the presence of $\mathrm{Zn}^{2+}$. Then $\alpha$-FXIIa converts PK to kallikrein (KAL) that enable a reciprocal hetero-activation of $\alpha$-FXII, leading to large amount of $\beta$-FXIIa and thereafter platelet $\mathrm{GP}_{\mathrm{Ib}}$-bound FXI activation. $\beta$-FXIIa is also able to activate the classic complement system pathway via $\mathrm{C} 1 \mathrm{r}$ and to a lesser extent $\mathrm{C} 1 \mathrm{~s}$ linking haemostasis and complement-mediated host defence [3].

CAS and PK also activate fibrinolysis and tissue proteolysis. HK linked to urokinase-type plasminogen activator receptor (uPAR) is able to activate pro-uPA into uPA that in turn activates plasminogen into matrix-bound plasmin. Moreover, BK induces tPA release by endothelial cells when linked to B1R [2].

Besides and related to CAS, the kallikrein/kinin system (KKS) is also activated [3]. CAS and PK also activate fibrinolysis and tissue proteolysis and are regulated by 


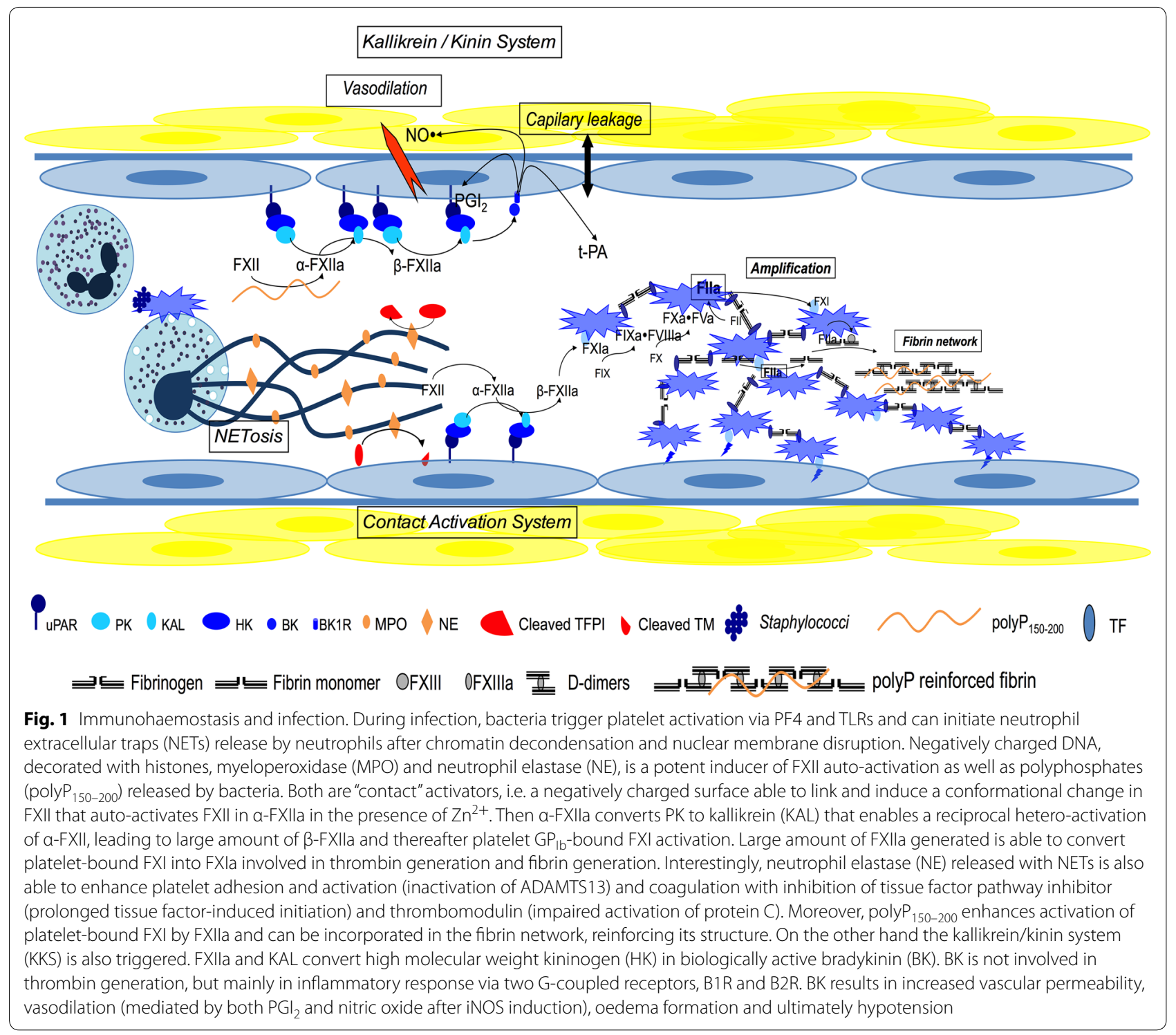

serpin $\mathrm{C} 1$ esterase inhibitor (C1-INH). A deficit (responsible for hereditary angioedema) or consumption (during septic shock but also after extracorporeal circulation) is responsible for increased permeability syndrome [31].

\section{Polyphosphates (polyP)}

PolyP are negatively charged inorganic phosphorous residue polymers, highly conserved in prokaryotes and eukaryotes. They are important source of energy, but are also involved in cell response. Half-life of polyP is very short due to their degradation by phosphatases [32, 33].

Medium-size soluble poly $\mathrm{P}_{60-80}$ are released by activated platelets and mast cells. They are able to induce FXII activation only if large amounts are present [34, 35]. PolyP $\mathrm{P}_{60-80}$ could also bind $\alpha$-FXIIa preventing further degradation, resulting in prolonged half-life. In the presence of fibrin polymers associated with polyP ${ }_{60-80}, \alpha$-FXIIa can activate fibrin-bound plasminogen in plasmin, resulting in "intrinsic" fibrinolytic activity overcoming antifibrinolytic properties [36, 37]. Interestingly, activated platelets could retain poly $\mathrm{P}_{60-80}$ on their surface assembled into insoluble spherical nanoparticles with divalent metal ions $\left(\mathrm{Ca}^{2+}, \mathrm{Zn}^{2+}\right)$. These nanoparticles provide higher polymer size and become able to trigger contact system activation $[38,39]$.

On the other hand, large-sized insoluble polyP ${ }_{150-200}$ are released by bacteria and yeasts. PolyP ${ }_{150-200}$ are able to support auto-activation of FXIIa and to promote thrombin generation independently of FXI activation. PolyP can bind FM resulting in clots with reduced 
stiffness and increased deformability [40]. Moreover, polyP $\mathrm{P}_{150-200}$ are incorporated in fibrin mesh, inhibiting fibrinolysis [34].

\section{Neutrophil extracellular traps (NETs)}

Neutrophils have long been considered as suicidal cells killing extracellular pathogens. Few years ago, biology of neutrophils has evolved for a more complex network linking innate immunity, adaptive immunity and haemostasis [41-43]. Neutrophils do not only engulf pathogens (phagocytosis) and release granules content, but also release their nuclear content, essentially histones and DNA fragments resulting in a net. These NETs support histones and other granule enzymes like myeloperoxidase (MPO) and neutrophil elastase (NE). These fragments are called NETs for neutrophils extracellular traps, and they enable to trap pathogens and blood cells, including platelets, in their meshes [44].

Two mechanisms of NETosis are described: a suicidal one [44-46] and a vital one, with functional anucleated phagocytic cell survival [47]. Finally, the plasma membrane bursts and NETs are released [48].

NETosis plays a critical role in host defence through innate immunity, but also through other procoagulant mechanisms:

i. Negatively charged DNA constitutes an activated surface for coagulation factors assembly, including contact phase;

ii. Enzymatic inhibition of tissue factor pathway inhibitor (TFPI) and thrombomodulin (TM) by neutrophil elastase;

iii. Direct recruitment and activation of platelets by histones [14].

Recent data support a direct activation by DNA and histones more than NETs themselves [49]. High levels of circulating histones have been evidenced in septic shock. Histone infusion induces intravascular coagulation with thrombocytopenia and increased D-dimers. Antihistone antibodies can prevent both lung and cardiac injuries in experimental models. C-reactive protein can bind histones and reduce histone-induced endothelial cell injury. $\mathrm{C}$-reactive protein infusion rescues histone-challenged mouse [50].

\section{Pathogen-induced modulation of blood coagulation (Table 1) Initiation of coagulation}

All bacteria can induce blood coagulation in a polyPdependent pathway as seen above. High molecular weight kininogen (HK) can also bind bacterial surface allowing a better activation by host proteases [51]. Interestingly, some bacteria use specific pathways to induce thrombin and fibrin generation [52-58].

\section{Degradation of fibrin clots}

Fibrin formation and pathogen entrapment are key features of host defence during infection. Fibrin(ogen) is fundamental to survive infection [59]. To evade fibrin, many bacteria developed fibrinolysis activators or expressed plasminogen receptors allowing activation by host tPA or uPA [60-76].

Outer membrane proteins (omptins) are surfaceexposed, transmembrane $\beta$-barrel proteases exposed by some gram-negative bacteria. They display fibrinolytic and procoagulant activities required for pathogenicity [71, 72]. Yersinia pestis is the agent of bubonic and pneumonic plague. Both associate haemorrhagic and thrombotic disorders and the presence of Pla, a direct activator of host plasminogen, require rough LPS. Pla is also able to promote fibrinolysis by activation of uPA, inactivation of serpins PAI- 1 and $\alpha_{2}$-antiplasmin and by cleavage of $\mathrm{C}$-terminal region of TAFI with reduced activation by thrombin-thrombomodulin complex [73, 74]. Pla is also able to cleave TFPI. Interestingly, dysplasminogenemia ( $\mathrm{Ala}^{601} \rightarrow \mathrm{Thr}$ ), present in about $2 \%$ of the Chinese, Korean and Japanese populations, confers a protection against plague. Homozygous individuals have a reduced plasminogen activity about $10 \%$ with fewer thrombotic events, but enhanced survival during infection by $Y$. pestis but also by group A streptococci and $S$. aureus requiring plasminogen activation for pathogenicity [75].

\section{Inactivation of fibrinolysis}

Inhibition of fibrinolysis is another way to promote clot stabilisation $[77,78]$.

\section{Inhibition of coagulation}

Bacteria can also block contact activation pathway [79, 80] or thrombin generation [81] in order to prevent host defence.

\section{Host defence peptides}

Innate immunity is mediated by cell activation via Tolllike receptors (TLRs). Resulting cationic and amphipathic small peptides (15-30 amino acids, $<10 \mathrm{kDa}$ ) have many biological properties including direct bactericidal effects, but also immunomodulation and angiogenesis. They have been named "host defence peptides" (HDPs) or "antimicrobial peptides" (AMPs).

In eukaryotes, we can identify defensins (disulphidestabilised peptides) and cathelicidins ( $\alpha$-helical or 
Table 1 Pathogen-induced modulation of blood coagulation

\begin{tabular}{|c|c|c|c|c|}
\hline Bacteria & Protein & Target & Result & References \\
\hline \multicolumn{5}{|c|}{ A-initiation of coagulation } \\
\hline All bacteria & PolyP & $\mathrm{FXII} \rightarrow \mathrm{FXIla}$ & Contact phase activation (FXI) & {$[51]$} \\
\hline \multirow[t]{6}{*}{ S. aureus } & Coagulase & $\mathrm{Fll} \rightarrow \mathrm{Flla}$ & Non-proteolytic activation & {$[52]$} \\
\hline & \multirow[t]{3}{*}{ von Willebrand binding protein (vWbp) } & VWF (endothelium) & S. aureus anchorage to endothelium & {$[53]$} \\
\hline & & $\mathrm{Fll} \rightarrow \mathrm{Flla}$ & Non-proteolytic activation & {$[52]$} \\
\hline & & vWbp-FIla $\rightarrow$ FXIII & Clot stabilisation & {$[53]$} \\
\hline & $\begin{array}{l}\text { Clumping factor } \mathrm{A}(\mathrm{Clf} A) \text { and fibronectin- } \\
\text { binding protein } \mathrm{A}(\mathrm{FnbpA})\end{array}$ & $\mathrm{Fg}$ & $\begin{array}{l}\text { S. aureus - platelet bridging and clot forma- } \\
\text { tion }\end{array}$ & {$[54]$} \\
\hline & Staphopains A and B (ScpA, ScpB) & $\mathrm{HK} \rightarrow \mathrm{BK}$ & Vascular leakage & {$[55,56]$} \\
\hline Group G streptococci & $\begin{array}{l}\text { Fibrinogen-binding protein (FOG) and } \\
\text { protein } G(P G)\end{array}$ & $\mathrm{FXII} \rightarrow \mathrm{FXIla}$ & $\begin{array}{l}\text { Contact phase complex assembly and } \\
\text { activation (FXI) at bacterial surface }\end{array}$ & {$[57]$} \\
\hline \multirow[t]{2}{*}{ B. anthracis } & \multirow[t]{2}{*}{ Zinc metalloprotease InhA1 } & $\mathrm{FX} \rightarrow \mathrm{FXa} / \mathrm{Fll} \rightarrow \mathrm{Flla}$ & Fibrin deposition & {$[57,58]$} \\
\hline & & ADAMTS13 inhibition & Platelet adhesion/activation by UL-vWF & {$[58]$} \\
\hline \multicolumn{5}{|c|}{$B$ - degradation of fibrin clot } \\
\hline B. burgdorferi & $\begin{array}{l}\text { Outer surface proteins (OspA and OspC) and } \\
\text { Erp proteins (ErpA, ErpC and ErpP) }\end{array}$ & Plasmin(ogen) & Plasminogen activation by tPA/uPA & {$[62]$} \\
\hline H. influenzae & Surface protein E (PE) & Plasmin(ogen) & Plasminogen activation by tPA/uPA & {$[63]$} \\
\hline Streptococcispp. & a-Enolase & Plasmin(ogen) & Plasminogen activation by tPA/uPA & {$[64-67]$} \\
\hline B. anthracis & a-Enolase and elongation factor tu & Plasmin(ogen) & Plasminogen activation by tPA/uPA & {$[66]$} \\
\hline \multirow[t]{2}{*}{ S.pyogenes } & \multirow{2}{*}{$\begin{array}{l}\text { Plasminogen-binding M-like protein (PAM) } \\
\text { and streptokinase (SK) }\end{array}$} & \multirow[t]{2}{*}{ Plasminogen } & Direct non-enzymatic activation & {$[51]$} \\
\hline & & & $\begin{array}{l}\text { Metalloprotease activation and tissue inva- } \\
\text { sion by PAM-bound SK.PM }\end{array}$ & {$[68,69]$} \\
\hline S. agalactiae & Skizzle (SkzL) & tPA/uPA & Enhanced plasminogen activation & {$[70]$} \\
\hline \multirow[t]{2}{*}{ Y.pestis } & \multirow[t]{2}{*}{ Omptin Pla } & Plasminogen & Direct activation in presence of LPS & {$[71]$} \\
\hline & & $\mathrm{PAI}-1 / \mathrm{TAFI} / \mathrm{a}_{2}-\mathrm{AP}$ & Inactivation of serpins & {$[72-74]$} \\
\hline S. enterica & Omptin PgtE & $\mathrm{PAI}-1 / \mathrm{a}_{2}-\mathrm{AP}$ & Inactivation of serpins & {$[76]$} \\
\hline \multicolumn{5}{|c|}{ C-inactivation of fibrinolysis } \\
\hline Group A streptococci & Collagen-like proteins (SCIA and ScIB) & TAFI and Flla & $\mathrm{TAFI} \rightarrow$ TAFla & {$[77,78]$} \\
\hline \multicolumn{5}{|c|}{ D-Inhibition of coagulation } \\
\hline Group A streptococci & Streptococcal inhibitor of complement (SIC) & HK & $\begin{array}{l}\text { Inhibition of HK binding and contact phase } \\
\text { activation }\end{array}$ & {$[79,80]$} \\
\hline S. aureus & $\begin{array}{l}\text { Staphylococcal superantigen-like protein } 10 \\
\text { (SSLP-10) }\end{array}$ & FII & Inhibition of platelet binding and activation & {$[81]$} \\
\hline
\end{tabular}

extended peptides). HDPs can be classified into three categories regarding their target on prokaryotes:

i. Plasma membrane-active peptides disrupting membrane integrity,

ii. Intracellular inhibitors of transcription or translational factors and

iii. Cell wall-active peptides interfering with cell wall synthesis and bacterial replication [82].

Limited proteolysis of many proteins involved in blood coagulation (activators as well as inhibitors) is now recognised as HDPs and may participate to host defence. Interestingly, the development of synthetic HDPs is a new therapeutic anti-infectious strategy regarding resistance of pathogens to (conventional) antibiotics [83].

\section{Serine protease-derived peptides}

Human serine proteases (including vitamin K-dependent blood coagulation factors and kallikrein system peptides) can be cleaved by proteases to generate C-terminal peptides with direct antimicrobial activities [84]. GKY25 is released from FIIa, FXa and FXIa after cleavage by neutrophil elastase [85]. This peptide is able to slightly reduce $P$. aeruginosa growth but also to significantly reduce both inflammatory response and mortality [86]. Bacteria are also able, mainly by unknown mechanisms, to generate HDPs from fibrinogen (GHR28) and high molecular weight kininogen (HKH20 and NAT26).

\section{Serpin-derived peptides}

Serpins (or serine protease inhibitors) can also generate HDPs. Heparin cofactor II (HCII) can be cleaved 
by neutrophil elastase after binding to glycosaminoglycan [87], and KYE28 displays antimicrobial properties against gram-negative and gram-positive bacteria but also against fungus [87]. Moreover, KYE28 can bind LPS dampening inflammatory response [88]. FFF21 derived from antithrombin also shares antimicrobial activity after permeabilisation of bacterial membrane [89]. Protein C inhibitor-derived SEK20 peptide displays antimicrobial activity [90]. Interestingly, platelets can bind PCI under activation resulting in high concentration of $\mathrm{PCI}$ at site of platelet recruitment as observed during infection [91].

\section{Diagnosis}

Activation of the coagulation cascade is a physiologic, innate and adaptive response during infection. This response can be overwhelmed, becoming hazardous and referred to as DIC meaning disseminated intravascular coagulation, as well as "death is coming" [92]. For many years, only two conditions were distinguished: "no DIC" and "DIC". This "schizophrenic" view of haemostasis needs to be reissued, as proposed by Dutt and Toh [93]: "The Ying-Yang of thrombin and protein C". There is indeed a continuum from adaptive to noxious thrombin generation. Moreover, DIC remains a medical paradigm for critical care physicians: clinical diagnosis is often (too) late and biological diagnosis (too) frequent in the absence of clinical signs or therapeutic opportunities [94].

\section{Clinical diagnosis}

Most patients with sepsis and septic shock do not present any clinical sign of "coagulopathy", while routine laboratory tests are disturbed. Clinical examination should focus on purpura, symmetric ischaemic limb gangrene (with pulses) [95] and diffuse oozing. A very specific sign is "retiform purpura", which is a netlike purpura reminiscent of livedo. However, unlike classic livedo, in which meshes are erythematous, meshes are here purpuric. The absence of induced bleeding on retrieval when the skin is punctured to a depth of 3 to $4 \mathrm{~mm}$ within a livid or purpuric area is a good indication of thrombotic microangiopathy [96].

\section{Laboratory criteria}

A single test will never be able to diagnose and stratify sepsis-induced coagulopathy. Only a combination of the presence of underlying disease associated with evidence of cellular activation in the vascular compartment (including endothelial cells, leucocytes and platelets), procoagulant activation, fibrinolytic activation, inhibitor consumption and end-organ damage or failure will allow such diagnosis.

\section{Underlying disease}

In sepsis and septic shock, vascular injury is central and prompted by different actors with overlapping kinetics, leading to difficulties in deciphering a sequential order [97].

Acute kidney injury (AKI) is present in about half patients, one-third of non-DIC patients versus four-fifth in DIC patients. This association between AKI and low platelets may be symptomatic of thrombotic microangiopathy (TMA) all the more that Ono et al. [98] reported low ADAMTS13 activity and high UL-vWF in septic shock-induced DIC. Nevertheless, there are two important differences: the presence of schizocytes and the absence of prolonged clotting times in TMAs $[99,100]$.

Hepatic injury is frequent, but remains mild to moderate, with a slight increase in liver enzymes and bilirubin and decrease in PT. On the other hand, severe hepatic ischaemia may lead to fulminant hypoxic hepatitis with very low PT, but also inhibitors AT and PC mimicking DIC with ischaemic limb gangrene with pulses [101].

\section{Cellular activation}

Only indirect markers of cellular activation are available; most of them are not routinely assessed. These markers could be soluble molecules (released by shedding or by proteolytic cleavage) or cell-derived microvesicles, including microparticles (MPs). The role of MPs in septic shock and infection has been discussed elsewhere [102-104].

Endothelial cells E-selectin(CD62E), or endothelial-leucocyte adhesion molecule-1 (ELAM-1), is only expressed by endothelial cells after cytokine stimulation. CD62E is involved in leucocyte recruitment at site of injury and could be released in the blood stream as free, soluble molecule (sCD62E) or membrane bound after MP shedding (CD62 ${ }^{+}$-MPs). sCD62E is dramatically increased during septic shock, especially in DIC patients [8], but was not associated with DIC diagnosis in one study $[105,106]$. Interestingly, CD62 ${ }^{+}$-MPs were not increased in septic shock due to proteolysis [8].

Endoglin (CD105, Eng) is a membrane protein expressed mainly by endothelial cells in the vascular repair and angiogenesis during inflammation [107]. It contains an arginine-glycine-aspartic acid (RGD) tripeptide sequence that enables cellular adhesion, through the binding of integrins or other RGD binding receptors that are present in the extracellular matrix. Membranebound CD105 is involved in leucocyte $\alpha 5 \beta 1$ activation, resulting in leucocyte recruitment and extravasation on the one hand and in angiogenesis on the other hand, whereas MMP-14-cleaved soluble (s)CD105 abolishes 
extravasation and inhibits angiogenesis [107]. CD105 plays a pivotal role in endothelial cell adhesion to mural cells [108]. Soluble CD105 overexpression is actually linked to other typical systemic and vascular inflammation states, as pre-eclampsia and HELLP syndrome, that are also characterised by a haemostatic activation/deregulation [109] and podocyturia [108]. We evidenced the presence of $\mathrm{CD} 105^{+}$-MPs during septic shock, especially in DIC patients $[8,110]$.

Endothelial cells also release soluble and microparticlebound EPCR. sEPCR is a marker of endothelial injury and severity [111], while EPCR ${ }^{+}$-MPs can display an anticoagulant and cytoprotective pattern in the bloodstream $[112,113]$.

Leucocytes Neutrophils and monocytes play a major role in sepsis-induced coagulopathy. After stimulation by thrombin and cytokines, monocytes could express TF and promote thrombin generation after cell membrane remodelling and phosphatidylserine (PhtdSer) exposition. Moreover, $\mathrm{TF}^{+}$-MPs of monocyte origin have been identified and could disseminate a procoagulant potential [7].

The role of neutrophils is more complex, involving both TF expression (fusion of $\mathrm{TF}^{+}$-MPs) [114] and NETs [115]. Direct evidence of the presence of NETs in bloodstream is lacking, but histones (or nucleosomes), free DNA and myeloperoxidase could be detected in plasma and are significantly increased in septic shock-induced DIC [116]. Recently, our group showed cytological modification of neutrophils in blood smears of patients with DIC [117]. Moreover, we evidenced neutrophil chromatin decondensation assessed by measuring neutrophil fluorescence (NEUT-SFL) using a routine automated flow cytometer Sysmex ${ }^{\mathrm{TM}} \mathrm{XN} 20$ [118].

Platelets Inflammation resulting in systemic inflammatory response syndrome (SIRS) is a potent inducer of both fibrinogen synthesis and platelet circulating pool mobilisation. Platelet count can reach 700-800 G/L, but thrombocytopenia can occur during sepsis. A "normal" valuethat is to say in the normal range-may be interpreted cautiously and represent patent consumption. Moreover, enumeration is not function. During sepsis-induced coagulopathy, platelet activation follows thrombin generation and does not support the propagation phase of haemostasis with impaired P-selectin, ADP, $\mathrm{Ca}^{2+}$ and cFXIII local supply.

Erythrocytes Schizocytes are fragmented erythrocytes and are the cornerstone of TMA diagnosis. They are frequently observed on blood smears during DIC and remain of poor value for DIC diagnosis [119].

\section{Procoagulant activation}

Routine coagulation tests evidence a prolongation of both prothrombin time (PT) and activated partial thromboplastin time (aPTT). Nevertheless, PT is the more accurate. aPTT is only slightly elevated during DIC due to inflammatory response and very high level of FVIII released by injured endothelial cells.

Evidence of thrombin generation can be evaluated by quantification of prothrombin fragment $1+2(\mathrm{~F} 1+2)$ and/or thrombin-antithrombin (TAT) complexes. These tests are not routinely available. Moreover, we evidenced the lack of discrimination of F1 +2 between DIC and non-DIC patients despite significant differences [8].

Fibrin formation is quantified by fibrinopeptide A (FpA) (with a 2:1 ratio), not available in routine [120]. Soluble fibrin monomers (FM) can be routinely quantified. They do not represent fibrin formation, but resting fibrin monomers not yet polymerised by FXIIIa. High FM can evidence increased production and/or defective polymerisation $[121,122]$. The accuracy of this biomarker is still matter of debate (see below) [123, 124].

\section{Fibrinolytic activation}

Fibrin(ogen) degradation products (FDPs) are heterogeneous small molecules generated by the action of plasmin on both fibrin network (secondary fibrinolysis) and fibrinogen (primary fibrinogenolysis). D-dimers (D-domain of two fibrin molecules stabilised by FXIIIa) are specific of fibrinolysis and must be preferred when available [125-127]. D-dimers sign thrombin generation, fibrin formation and polymerisation then fibrinolysis, while the absence of D-dimers could represent defective fibrinolysis despite the presence of fibrin. Other markers could be useful but are not available in routine laboratories: PAP (plasmin-antiplasmin complexes), tPA and PAI-1 $[128,129]$. Both tPA and PAI-1 are dramatically increased during septic shock, regardless of DIC diagnosis. Early inhibition of fibrinolysis during sepsis-induced coagulopathy may cause diagnostic delay regarding the importance of FDPs in DIC diagnosis.

\section{Inhibitors consumption}

Sustained thrombin generation leads to activation, then consumption, of regulatory mechanisms. TFPI is decreased during DIC [130]. Antithrombin can be-and should be-routinely assessed during sepsis-induced coagulopathy. The absence of low AT level challenges the diagnosis of DIC [131]. Concerning the TM-APC pathway, assessment is complex. PC is decreased by consumption, but APC is increased, at least at the beginning of sepsis. Moreover, soluble forms of EPCR (sEPCR) [111] and TM (sTM) [132] can be found in plasma of septic patients and are correlated to vascular injury. 


\section{Global assessment of haemostasis}

Thromboelastography (TEG) and rotational thromboelastometry $\left(\right.$ ROTEM $\left.^{\mathrm{TM}}\right)$ are routinely used in operative theatres to monitor blood coagulation and "assess global haemostasis" [133]. Interestingly, they can also evaluate fibrinolysis at 30 and $60 \mathrm{~min}$. Nevertheless, a recent Cochrane review concluded that there was little or no evidence of the accuracy of such devices, strongly suggesting that they should only be used for research $[99,100]$. Few data are available regarding septic shock-induced coagulation/coagulopathy. A prospective study comparing septic shock patients, surgical patients and healthy volunteers evidences a hypocoagulability during DIC [134]. In this study, we may hypothesise that DIC patients were in "fibrinolytic" phase.

\section{Scoring systems}

Different scoring systems have been developed to ensure DIC diagnosis and are discussed in supplementary data (Additional file 1, Additional file 3: Table S1).

\section{New therapeutic opportunities?}

A syllogism precludes anticoagulant therapy during severe sepsis and septic shock: "more severe is the infection, more thrombin is generated", "more thrombin is generated, more organ failure and death supervene", so "more you prevent thrombin generation, more you will improve your patient with severe infection". This view forgets that haemostasis is mandatory to survive sepsis via many pathways, including newly recognised immunothrombosis and HDPs. In fact, "anticoagulant" treatments disrupt a tight equilibrium between pathogen and adaptive host response and may lead to more deaths in a group of patients (adaptive haemostasis) and to fewer deaths in another group (noxious haemostasis). Recognition of "noxious haemostasis" remains a medical paradigm for critical care physicians. Negative therapeutic interventions [135, 136], drotrecogin alfa withdrawal [137], but also emerging concept of immunothrombosis [14] could argue for a radical "tabula rasa" regarding coagulation during septic shock. The debate is still open and can be summarised in one question: "Should all patients with sepsis receive anticoagulation?" [138, 139]. Finally, whether immunohaemostasis/DIC clinical assessment is reliable remains a major issue (Fig. 2).

A mini-review of current (and past) therapies is provided in supplementary data (Additional file 1, Additional file 4: Table S2, Additional file 5: Table S3 and Additional file 6: Figure S2) regarding:

i. limitation of thrombin and fibrin generation,

ii. DIC with thrombotic/multiple organ failure pattern, iii. DIC with haemorrhagic pattern.
In the following section, we will present an overview of therapies focused on immunohaemostasis activation.

\section{Inhibition of contact pathway}

Contact pathway is not necessary for "normal" haemostasis. FXII(a) and FXI(a) are new targets to develop "safe" antithrombotic drugs without antihaemostatic effects [140-142]. Moreover, these drugs could improve hypotension targeting bradykinin release.

\section{C1-inhibitor}

C1-inhibitor regulates both complement activation and FXII and could improve both capillary leakage and hypotension on the one hand and contact phase-induced thrombin generation on the other. As other serpins, C1-inhibitor is dramatically reduced in septic shock and C1-inhibitor supplementation could improve patients or renal function in short randomised trials [143-145]. Nevertheless, no large randomised trial can support its use. Interestingly, bradykinin receptor antagonist icatibant had no effect on a porcine model of septic shock [146].

\section{FXII blockade}

In a baboon model challenged with a lethal dose of E. coli, the monoclonal antibody C6B7 directed against FXIIa improved survival with higher blood pressure. In the treated group, the inflammatory response was reduced with lower IL-6 and neutrophil elastase release as well as complement activation. Inhibition of FXIIa was obvious with reduced BK released and fibrinolysis. Nevertheless, both groups experiment DIC with low platelet count, low fibrinogen and low FV [147]. Another FXIIa monoclonal blocking antibody is 3F7. This antibody seems to be safe as an anticoagulant in experimental extracorporeal membrane oxygenation model, with reduced bleeding compared to heparin, but no data are yet available regarding septic shock [148].

\section{FXI blockade}

14E11 is an anti-FXI monoclonal antibody that blocks FXI activation by FXIIa but not by FIIa. 14E11 displays antithrombotic properties. This molecule was used in mouse polymicrobial sepsis. Inflammation and coagulopathy were improved as well as survival after 14E11 treatment up to $12 \mathrm{~h}$ after bowel perforation onset. Clotting time was not modified, and no bleeding could be evidenced in this model [149].

Interestingly, FXI KO mice $\left(\mathrm{FXI}^{-/-}\right)$evidence increased inflammatory response with impaired neutrophil functions-but not haemorrhage in lungs-in a model of Klebsiella pneumoniae and Streptococcus pneumoniae pneumonia resulting in an increased mortality. Inhibition 


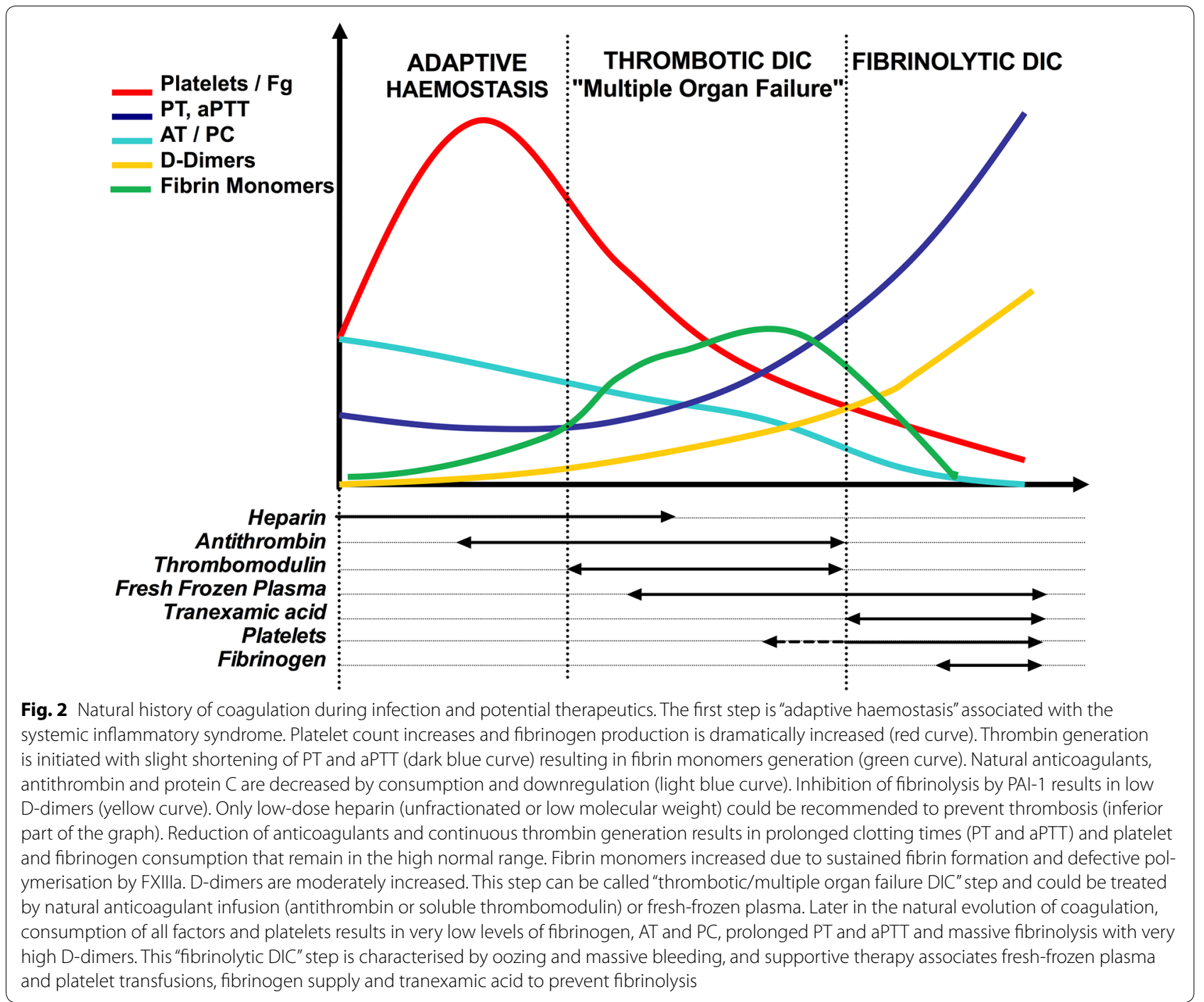

of FXI activation by FXIIa does not reproduce this pattern [150].

A genetically engineered fusion protein (MR1007) containing anti-CD14 antibody (to block LPS receptor) and the modified second domain of bikunin (with anti-FXIa activity) improves survival in a rabbit model of sepsis without increasing spontaneous bleeding [151].

\section{Inhibition of platelet functions in thrombus formation}

Platelets are important immune cells, and thrombocytopenia is associated with an increased mortality in septic shock [152, 153]. Few data support a benefit of previous aspirin treatment in community-onset pneumonia with [154] or without septic shock [155]. In a retrospective study of patients with septic shock, chronic antiplatelet treatment was not associated with reduced mortality [156]. There are no data to support introduction of antiplatelet therapy or to transfuse platelets in the absence of obvious thrombocytopenia with bleeding.

\section{Inhibition of polyP}

Targeting polyP is a new opportunity in the treatment of contact phase-induced thrombosis, including immunothrombosis, but some of them are toxic in vivo and cannot be used in humans (polymyxin B, polyethylenimine and polyamidoamine dendrimers) [157].

\section{Universal heparin reversal agents (UHRAs)}

UHRAs have been developed to reverse heparin effects but also displayed anticoagulant effects. UHRA-9 and UHRA-10 specifically inhibit polyP and prove antithrombotic effects without increasing bleeding in a mouse model of arterial thrombosis [158]. Nevertheless, these agents have not been used in experimental septic shock to date. 


\section{Phosphatases}

Platelet-derived polyP are rapidly degraded by phosphatases. During septic shock, alkaline phosphatase activity is dramatically decreased and could enhance polyP activity. A recombinant human alkaline phosphatase (RecAP) is able to improve renal function due to acute kidney injury during septic shock [159-161]. Moreover, RecAP inhibits platelet activation ex vivo by converting ADP in adenosine and reverse hyperactivity of septic shock-derived platelets [162]. Effects on polyP were not specifically studied in this experimental study but cannot be excluded.

\section{Dabrafenib}

Dabrafenib is a B-Raf kinase inhibitor indicated in unresectable or metastatic melanoma with BRAF V600E mutation. This molecule has anti-inflammatory effects on polyP-mediated vascular disruption and cytokine production. In a mouse model of CLP-induced septic shock, administration of Dabrafenib 12 and $50 \mathrm{~h}$ after ligation improves survival [163].

\section{Inhibition of NETs/histones \\ Deoxyribonuclease 1 (DNase 1)}

Deoxyribonuclease 1 or dornase alfa (Pulmozyme ${ }^{\circledR}$ ) is an inhaled potent inhibitor of bacterial DNA used in patients with cystic fibrosis. Few experimental data are available regarding NETs. In a mouse model of thrombosis, DNase 1 infusion disassembles NETs and prevents thrombus formation [164]. Interestingly, in a CLP model of sepsis, DNase 1 delayed-but not early-infusion reduces organ failure and improves outcome [165]. More recently, DNase 1 infusion in mice challenged with LPS, E. coli or S. aureus reduces thrombin generation and platelet aggregation and improves microvascular perfusion [166] and survival [167].

\section{Interferon- $\lambda 1 /$ IL-29}

IFN- $\lambda 1 /$ IL-29 is a potent antiviral cytokine able to prevent NETs release induced by septic shock sera or platelet-derived polyP after phosphorylation of mammalian target of rapamycin (mTOR) to downregulate autophagy. Moreover, IFN- $\lambda 1 /$ IL-29 does not alter neutrophil viability and ROS production preserving phagocytosis. IFN- $\lambda 1 / \mathrm{IL}-29$ has a strong antithrombotic activity in experimental arterial thrombosis but could also regulate immunohaemostasis [168].

\section{Conclusion: evidence-based versus pragmatic medicine}

Up to date, it is not possible to propose a unique strategy to diagnose and treat coagulation disorders during infection and septic shock. On the one hand, an "old view" considered activation of blood coagulation as one of the principal ways to die and thrombin as the principal suspect. This view was the rationale for anticoagulation during septic shock, with many experimental data supporting it. Nevertheless, all clinical trials-with the exception of PROWESS trial-failed to improve survival in unselected septic shock patients. On the other hand, recent experimental and clinical data support a beneficial role of blood coagulation to survive sepsis, including immunohaemostasis. The first step to improve patients' care is to stratify the "coagulopathy". A combination of biological tests must be used daily, eventually combined in scores. We believe that JAAM 2006 and JAAM-DIC scores, taking into account the inflammatory syndrome and evolution, are the most appropriate. New markers of cell activation may be of interest. The second step is the choice of therapeutic intervention. Treatment of both infection and shock without delay is mandatory. Then, anticoagulation may be considered. To date, no recommendation can be made according to international guidelines with a high level of proof. Nevertheless, three different patterns could be recognised (Fig. 2):

i. Absence of obvious coagulopathy with high platelet count, low D-dimers, subnormal PT and AT requiring only prevention of thrombosis by unfractionated or low molecular weight heparins.

ii. Thrombotic/multiple organ failure coagulopathy (also referred as thrombotic DIC) with "low normal" platelet count, prolonged PT, decreased AT and mild to moderate D-dimers level; clinical presentation may combine organ failure and cutaneous signs like symmetric limb gangrene with pulses and retiform purpura. Antithrombin and recombinant soluble thrombomodulin must be considered. New treatments targeting FXIIa, FXIa, polyP and NETs preventing thrombosis are in development and improve survival in experimental sepsis or septic shock. They have not yet been tested in humans.

iii. Haemorrhagic/fibrinolytic coagulopathy with very low platelets, fibrinogen and AT, prolonged coagulation times and clinical oozing. Massive transfusion of freshfrozen plasma, platelets and fibrinogen is required, with antifibrinolytic drugs.

New clinical trials are necessary to support this view and to improve patients' care.

\section{Additional files}

Additional file 1. Supplementary data.

Additional file 2: Figure S1. Physiology of thrombin generation.

Additional file 3: Table S1. DIC scoring systems.

Additional file 4: Table S2. Efficacy of anticoagulants in septic shock.

Additional file 5: Table S3. Effect of antithrombin in pneumoniainduced septic shock with DIC (observational nationwide study) ${ }^{40}$.

Additional file 6: Figure S2. Timing of anticoagulant therapy. 


\begin{abstract}
Abbreviations
ADAMTS13: a disintegrin and metalloprotease with thrombospondin type 1 motif; CAS: contact activation system; DIC: disseminated intravascular coagulation; FDPs: fibrin(ogen) degradation products; HDPs: host defence peptides; HK: high molecular weight kallikrein; ISTH: International Society for Thrombosis and Haemostasis; JAAM: Japanese Association for Acute Medicine; KAL: kallikrein; KKS: kallikrein/kinin system; MPO: myeloperoxidase; MPs: microparticles; NE: neutrophil elastase; NETs: neutrophil extracellular traps; PCI: protein C inhibitor; Pg: plasminogen; polyP: polyphosphates; SK: streptokinase; TAFI: thrombin-activatable fibrinolysis inhibitor; TMAs: thrombotic microangiopathies; UL-vWF: ultralarge von Willebrand factor.
\end{abstract}

\section{Authors' contributions}

$X D$ was the primary author responsible for literature search and review. XD, JH and FM were involved in the generation of the first version of the manuscript and then in critical revision, editing and generation of revised manuscript. All authors read and approved the final manuscript.

\section{Authors' information}

XD (MD, Ph.D.), consultant, JH (MD, Ph.D.), consultant and lecturer and FM (MD, Ph.D.), consultant, professor and head, all in critical care medicine-service de réanimation médicale, Nouvel Hôpital Civil—Hôpitaux Universitaires de Strasbourg, Strasbourg (France).

\section{Author details}

${ }^{1}$ Université de Strasbourg, Faculté de Médecine \& Hôpitaux Universitaires de Strasbourg, Service de Réanimation, Nouvel Hôpital Civil, Strasbourg, France. ${ }^{2}$ INSERM (French National Institute of Health and Medical Research), UMR 1260, Regenerative Nanomedicine (RNM), FMTS, Université de Strasbourg, Strasbourg, France. ${ }^{3}$ INSERM, EFS Grand Est, BPPS UMR-S 949, Université de Strasbourg, Strasbourg, France.

\section{Acknowledgements}

We want to thank Asaël BERGER (MD) for literature search.

\section{Competing interests}

The authors declare that they have no competing interests.

\section{Availability of data and materials}

Not applicable for this review.

\section{Consent for publication}

Not applicable for this review.

\section{Ethics approval and consent to participate}

Not applicable for this review.

\section{Funding}

No funding was obtained for the creation of this review.

\section{Publisher's Note}

Springer Nature remains neutral with regard to jurisdictional claims in published maps and institutional affiliations.

Received: 12 May 2017 Accepted: 20 November 2017

Published online: 02 December 2017

\section{References}

1. Lane DA, Philippou H, Huntington JA. Directing thrombin. Blood. 2005;106(8):2605-12.

2. Schmaier AH. The contact activation and kallikrein/kinin systems: pathophysiologic and physiologic activities. J Thromb Haemost. 2016;14(1):28-39.

3. Long AT, Kenne E, Jung R, Fuchs TA, Renne T. Contact system revisited: an interface between inflammation, coagulation, and innate immunity. J Thromb Haemost. 2016;14(3):427-37.

4. Lerolle N, Carlotti A, Melican K, et al. Assessment of the interplay between blood and skin vascular abnormalities in adult purpura fulminans. Am J Respir Crit Care Med. 2013;188(6):684-92.
5. Arman M, Krauel K, Tilley DO, et al. Amplification of bacteria-induced platelet activation is triggered by FcyRIIIA, integrin allb $\beta 3$, and platelet factor 4. Blood. 2014;123(20):3166-74.

6. Morrissey JH. Polyphosphate: a link between platelets, coagulation and inflammation. Int J Hematol. 2012;95(4):346-52.

7. Nieuwland R, Berckmans RJ, McGregor S, et al. Cellular origin and procoagulant properties of microparticles in meningococcal sepsis. Blood. 2000;95(3):930-5.

8. Delabranche X, Boisrame-Helms J, Asfar P, et al. Microparticles are new biomarkers of septic shock-induced disseminated intravascular coagulopathy. Intensive Care Med. 2013;39(10):1695-703.

9. Xu J, Zhang X, Pelayo R, et al. Extracellular histones are major mediators of death in sepsis. Nat Med. 2009;15(11):1318-21.

10. Kambas K, Mitroulis I, Ritis K. The emerging role of neutrophils in thrombosis-the journey of TF through NETs. Front Immunol. 2012;3:385.

11. Marshall JC. Why have clinical trials in sepsis failed? Trends Mol Med. 2014;20(4):195-203.

12. Dellinger RP, Levy MM, Rhodes A, et al. Surviving sepsis campaign: international guidelines for management of severe sepsis and septic shock: 2012. Crit Care Med. 2013:41(2):580-637.

13. Iba T, Gando S, Thachil J. Anticoagulant therapy for sepsis-associated disseminated intravascular coagulation: the view from Japan. J Thromb Haemost. 2014;12(7):1010-9.

14. Engelmann B, Massberg S. Thrombosis as an intravascular effector of innate immunity. Nat Rev Immunol. 2013;13(1):34-45.

15. Claushuis TA, de Stoppelaar SF, Stroo I, et al. Thrombin contributes to protective immunity in pneumonia-derived sepsis via fibrin polymerization and platelet-neutrophil interactions. JThromb Haemost. 2017;15(4):744-57.

16. Angus DC, van der Poll T. Severe sepsis and septic shock. N Engl J Med. 2013;369(9):840-51.

17. van der Poll T, Herwald $\mathrm{H}$. The coagulation system and its function in early immune defense. Thromb Haemost. 2014;112(4):640-8.

18. Wada H, Matsumoto T, Yamashita Y. Diagnosis and treatment of disseminated intravascular coagulation (DIC) according to four DIC guidelines. J Intensive Care. 2014:2(1):15.

19. Gando S, Wada H, Thachil J. Scientific and Standardization Committee on DIC of the International Society on Thrombosis and Haemostasis (ISTH). Differentiating disseminated intravascular coagulation (DIC) with the fibrinolytic phenotype from coagulopathy of trauma and acute coagulopathy of trauma-shock (COT/ACOTS). J Thromb Haemost. 2013;11(5):826-35.

20. Gando S, Otomo Y. Local hemostasis, immunothrombosis, and systemic disseminated intravascular coagulation in trauma and traumatic shock. Crit Care. 2015;19:72.

21. Fourrier F. Severe sepsis, coagulation, and fibrinolysis: dead end or one way? Crit Care Med. 2012;40(9):2704-8.

22. Levi M. The coagulant response in sepsis and inflammation. Hamostaseologie 2010; 30(1): 10-2, 4-6.

23. Levi $\mathrm{M}$, van der Poll T. Endothelial injury in sepsis. Intensive Care Med. 2013;39(10):1839-42.

24. Versteeg HH, Heemskerk JW, Levi M, Reitsma PH. New fundamentals in hemostasis. Physiol Rev. 2013;93(1):327-58.

25. Krem MM, Rose T, Di Cera E. Sequence determinants of function and evolution in serine proteases. Trends Cardiovasc Med. 2000;10(4):171-6.

26. Davidson CJ, Tuddenham EG, McVey JH. 450 million years of hemostasis. J Thromb Haemost. 2003:1 (7):1487-94.

27. Oikonomopoulou K, Ricklin D, Ward PA, Lambris JD. Interactions between coagulation and complement-their role in inflammation. Semin Immunopathol. 2012;34(1):151-65.

28. Berends ET, Kuipers A, Ravesloot MM, Urbanus RT, Rooijakkers SH. Bacteria under stress by complement and coagulation. FEMS Microbiol Rev. 2014;38(6):1146-71.

29. White GC 2nd. The partial thromboplastin time: defining an era in coagulation. J Thromb Haemost. 2003;1(11):2267-70.

30. Evans CE, Zhao YY. Impact of thrombosis on pulmonary endothelial injury and repair following sepsis. Am J Physiol Lung Cell Mol Physiol. 2017;312(4):L441-51.

31. Frick IM, Bjorck L, Herwald $H$. The dual role of the contact system in bacterial infectious disease. Thromb Haemost. 2007;98(3):497-502. 
32. Brown MR, Kornberg A. Inorganic polyphosphate in the origin and survival of species. Proc Natl Acad Sci USA. 2004;101(46):16085-7.

33. Kornberg A, Rao NN, Ault-Riche D. Inorganic polyphosphate: a molecule of many functions. Annu Rev Biochem. 1999;68:89-125.

34. Smith SA, Choi SH, Davis-Harrison R, et al. Polyphosphate exerts differential effects on blood clotting, depending on polymer size. Blood. 2010;116(20):4353-9.

35. Semeraro N, Ammollo CT, Semeraro F, Colucci M. Sepsis, thrombosis and organ dysfunction. Thromb Res. 2012;129(3):290-5

36. Mitchell JL, Lionikiene AS, Georgiev G, et al. Polyphosphate colocalizes with factor XII on platelet-bound fibrin and augments its plasminogen activator activity. Blood. 2016;128(24):2834-45.

37. Maas C. Polyphosphate strikes back. Blood. 2016;128(24):2754-6.

38. Verhoef JJ, Barendrecht AD, Nickel KF, et al. Polyphosphate nanoparticles on the platelet surface trigger contact system activation. Blood. 2017;129(12):1707-17.

39. Weitz JI, Fredenburgh JC. Platelet polyphosphate: the long and the short of it. Blood. 2017:129(12):1574-5.

40. Whyte CS, Chernysh IN, Domingues MM, et al. Polyphosphate delays fibrin polymerisation and alters the mechanical properties of the fibrin network. Thromb Haemost. 2016;116(5):897-903.

41. Mocsai A. Diverse novel functions of neutrophils in immunity, inflammation, and beyond. J Exp Med. 2013;210(7):1283-99.

42. Amulic B, Cazalet C, Hayes GL, Metzler KD, Zychlinsky A. Neutrophil function: from mechanisms to disease. Annu Rev Immunol. 2012;30:459-89.

43. Stiel L, Meziani F, Helms J. Neutrophil activation during septic shock. Shock. 2017. https://doi.org/10.1097/SHK.0000000000000980.

44. Brinkmann V, Reichard U, Goosmann C, et al. Neutrophil extracellular traps kill bacteria. Science. 2004;303(5663):1532-5.

45. Fuchs TA, Abed U, Goosmann C, et al. Novel cell death program leads to neutrophil extracellular traps. J Cell Biol. 2007;176(2):231-41.

46. Papayannopoulos V, Metzler KD, Hakkim A, Zychlinsky A. Neutrophil elastase and myeloperoxidase regulate the formation of neutrophil extracellular traps. J Cell Biol. 2010;191(3):677-91.

47. Pilsczek FH, Salina D, Poon KK, et al. A novel mechanism of rapid nuclear neutrophil extracellular trap formation in response to Staphylococcus aureus. J Immunol. 2010;185(12):7413-25.

48. Phillipson M, Kubes P. The neutrophil in vascular inflammation. Nat Med. 2011:17(11):1381-90

49. Noubouossie DF, Whelihan MF, Yu YB, et al. In vitro activation of coagulation by human neutrophil DNA and histone proteins but not neutrophil extracellular traps. Blood. 2017;129(8):1021-9.

50. Abrams ST, Zhang N, Dart C, et al. Human CRP defends against the toxicity of circulating histones. J Immunol. 2013;191(5):2495-502.

51. Smeesters PR, McMillan DJ, Sriprakash KS. The streptococcal M protein: a highly versatile molecule. Trends Microbiol. 2010;18(6):275-82.

52. McAdow M, Missiakas DM, Schneewind O. Staphylococcus aureus secretes coagulase and von Willebrand factor binding protein to modify the coagulation cascade and establish host infections. J Innate Immun. 2012:4(2):141-8

53. Thomer L, Schneewind O, Missiakas D. Multiple ligands of von Willebrand factor-binding protein (VWbp) promote Staphylococcus aureus clot formation in human plasma. J Biol Chem. 2013;288(39):28283-92.

54. Fitzgerald JR, Loughman A, Keane F, et al. Fibronectin-binding proteins of Staphylococcus aureus mediate activation of human platelets via fibrinogen and fibronectin bridges to integrin GPIIb/IIla and lgG binding to the FcyRlla receptor. Mol Microbiol. 2006;59(1):212-30.

55. Imamura T, Tanase S, Szmyd G, Kozik A, Travis J, Potempa J. Induction of vascular leakage through release of bradykinin and a novel kinin by cysteine proteinases from Staphylococcus aureus. J Exp Med. 2005;201(10):1669-76

56. Wollein Waldetoft K, Svensson L, Morgelin M, et al. Streptococcal surface proteins activate the contact system and control its antibacterial activity. J Biol Chem. 2012;287(30):25010-8

57. Chung MC, Popova TG, Jorgensen SC, et al. Degradation of circulating von Willebrand factor and its regulator ADAMTS13 implicates secreted Bacillus anthracis metalloproteases in anthrax consumptive coagulopathy. J Biol Chem. 2008;283(15):9531-42.
58. Kastrup CJ, Boedicker JQ, Pomerantsev AP, et al. Spatial localization of bacteria controls coagulation of human blood by 'quorum acting'. Nat Chem Biol. 2008:4(12):742-50.

59. Sun $H$, Wang $X$, Degen JL, Ginsburg D. Reduced thrombin generation increases host susceptibility to group A streptococcal infection. Blood. 2009;113(6):1358-64

60. Rivera J, Vannakambadi G, Hook M, Speziale P. Fibrinogen-binding proteins of Gram-positive bacteria. Thromb Haemost. 2007;98(3):503-11.

61. Degen JL, Bugge $T H$, Goguen JD. Fibrin and fibrinolysis in infection and host defense. J Thromb Haemost. 2007;5(Suppl 1):24-31.

62. Brissette CA, Haupt K, Barthel D, et al. Borrelia burgdorferi infectionassociated surface proteins ErpP, ErpA, and ErpC bind human plasminogen. Infect Immun. 2009;77(1):300-6.

63. Barthel D, Singh B, Riesbeck K, Zipfel PF. Haemophilus influenzae uses the surface protein $E$ to acquire human plasminogen and to evade innate immunity. J Immunol. 2012;188(1):379-85.

64. Pancholi V, Fischetti VA. alpha-enolase, a novel strong plasmin(ogen) binding protein on the surface of pathogenic streptococci. J Biol Chem. 1998;273(23):14503-15.

65. Bergmann S, Rohde M, Chhatwal GS, Hammerschmidt S. Alpha-enolase of Streptococcus pneumoniae is a plasmin(ogen)-binding protein displayed on the bacterial cell surface. Mol Microbiol. 2001;40(6):1273-87.

66. Chung MC, Tonry JH, Narayanan A, et al. Bacillus anthracis interacts with plasmin(ogen) to evade C3b-dependent innate immunity. PLOS ONE. 2011;6(3):0018119.

67. Floden AM, Watt JA, Brissette CA. Borrelia burgdorferi enolase is a surface-exposed plasminogen binding protein. PLoS ONE. 2011;6(11):8.

68. Bisno AL, Brito MO, Collins CM. Molecular basis of group A streptococcal virulence. Lancet Infect Dis. 2003;3(4):191-200.

69. Verhamme IM, Panizzi PR, Bock PE. Pathogen activators of plasminogen. I Thromb Haemost. 2015:13(1):12939.

70. Wiles KG, Panizzi P, Kroh HK, Bock PE. Skizzle is a novel plasminogenand plasmin-binding protein from Streptococcus agalactiae that targets proteins of human fibrinolysis to promote plasmin generation. $J$ Biol Chem. 2010;285(27):21153-64.

71. Stathopoulos C. Structural features, physiological roles, and biotechnological applications of the membrane proteases of the OmpT bacterial endopeptidase family: a micro-review. Membr Cell Biol. 1998;12(1):1-8.

72. Haiko J, Suomalainen M, Ojala T, Lahteenmaki K, Korhonen TK. Invited review: breaking barriers-attack on innate immune defences by omptin surface proteases of enterobacterial pathogens. Innate Immun. 2009:15(2):67-80.

73. Korhonen TK, Haiko J, Laakkonen L, Jarvinen HM, Westerlund-Wikstrom B. Fibrinolytic and coagulative activities of Yersinia pestis. Front Cell Infect Microbiol. 2013;3:35.

74. Korhonen TK. Fibrinolytic and procoagulant activities of Yersinia pestis and Salmonella enterica. J Thromb Haemost. 2015;13(1):12932.

75. Ooe A, Kida M, Yamazaki T, et al. Common mutation of plasminogen detected in three Asian populations by an amplification refractory mutation system and rapid automated capillary electrophoresis. Thromb Haemost. 1999:82(4):1342-6.

76. Thomassin JL, Brannon JR, Gibbs BF, Gruenheid S, Le Moual H. OmpT outer membrane proteases of enterohemorrhagic and enteropathogenic Escherichia coli contribute differently to the degradation of human LL-37. Infect Immun. 2012:80(2):483-92.

77. Bengtson SH, Sanden C, Morgelin M, et al. Activation of TAFI on the surface of Streptococcus pyogenes evokes inflammatory reactions by modulating the kallikrein/kinin system. J Innate Immun. 2009;1 (1):18-28.

78. Mook-Kanamori BB, Valls Seron M, Geldhoff M, et al. Thrombinactivatable fibrinolysis inhibitor influences disease severity in humans and mice with pneumococcal meningitis. J Thromb Haemost. 2015;13(11):2076-86

79. Akesson P, Herwald H, Rasmussen M, et al. Streptococcal inhibitor of complement-mediated lysis (SIC): an anti-inflammatory virulence determinant Microbiology. 2010:156(Pt 12):3660-8.

80. Frick IM, Shannon O, Akesson P, et al. Antibacterial activity of the contact and complement systems is blocked by SIC, a protein secreted by Streptococcus pyogenes. J Biol Chem. 2011;286(2):1331-40. 
81. Itoh S, Yokoyama R, Kamoshida G, et al. Staphylococcal superantigenlike protein 10 (SSL10) inhibits blood coagulation by binding to prothrombin and factor Xa via their gamma-carboxyglutamic acid (Gla) domain. J Biol Chem. 2013;288(30):21569-80.

82. Yount NY, Yeaman MR. Peptide antimicrobials: cell wall as a bacterial target. Ann N Y Acad Sci. 2013;1277:127-38.

83. Yount NY, Yeaman MR. Emerging themes and therapeutic prospects for anti-infective peptides. Annu Rev Pharmacol Toxicol. 2012;52:337-60.

84. Kasetty G, Papareddy P, Kalle M, et al. The C-terminal sequence of several human serine proteases encodes host defense functions. J Innate Immun. 2011:3(5):471-82.

85. Papareddy P, Rydengard V, Pasupuleti M, et al. Proteolysis of human thrombin generates novel host defense peptides. PLoS Pathog. 2010;6(4):1000857.

86. Kalle M, Papareddy P, Kasetty G, et al. Host defense peptides of thrombin modulate inflammation and coagulation in endotoxin-mediated shock and Pseudomonas aeruginosa sepsis. PLoS ONE. 2012;7(12):13.

87. Kalle M, Papareddy P, Kasetty $G$, et al. Proteolytic activation transforms heparin cofactor II into a host defense molecule. J Immunol. 2013;190(12):6303-10

88. Kalle M, Papareddy P, Kasetty G, et al. A peptide of heparin cofactor II inhibits endotoxin-mediated shock and invasive Pseudomonas aeruginosa infection. PLoS ONE. 2014;9(7):e102577.

89. Papareddy $\mathrm{P}$, Kalle M, Bhongir RK, Morgelin M, Malmsten M Schmidtchen A. Antimicrobial effects of helix D-derived peptides of human antithrombin III. J Biol Chem. 2014;289(43):29790-800.

90. Malmstrom E, Morgelin M, Malmsten M, et al. Protein C inhibitor-a novel antimicrobial agent. PLoS Pathog. 2009;5(12):18.

91. Rieger D, Assinger A, Einfinger K, Sokolikova B, Geiger M. Protein C inhibitor (PCI) binds to phosphatidylserine exposing cells with implications in the phagocytosis of apoptotic cells and activated platelets. PLOS ONE. 2014;9(7):e101794.

92. Spero $\mathrm{JA}$, Lewis $\mathrm{JH}$, Hasiba U. Disseminated intravascular coagulation. Findings in 346 patients. Thromb Haemost. 1980;43(1):28-33.

93. Dutt T, Toh CH. The Yin-Yang of thrombin and activated protein C. Br J Haematol. 2008;140(5):505-15.

94. Wada H, Thachil J, Di Nisio M, et al. Guidance for diagnosis and treatment of DIC from harmonization of the recommendations from three guidelines. J Thromb Haemost. 2013;4(10):12155.

95. Warkentin TE. Ischemic Limb Gangrene with Pulses. N Engl J Med. 2015;373(7):642-55

96. Lipsker D. Ischemic limb gangrene with pulses [Correspondance]. N Engl J Med. 2015;373(24):2385-6.

97. Shapiro NI, Schuetz P, Yano K, et al. The association of endothelial cell signaling, severity of illness, and organ dysfunction in sepsis. Crit Care. 2010;14(5):R182.

98. Ono T, Mimuro J, Madoiwa S, et al. Severe secondary deficiency of von Willebrand factor-cleaving protease (ADAMTS13) in patients with sepsis-induced disseminated intravascular coagulation: its correlation with development of renal failure. Blood. 2006;107(2):528-34.

99. George JN, Nester CM. Syndromes of thrombotic microangiopathy. N Engl J Med. 2014;371(7):654-66.

100. Hunt BJ. Bleeding and coagulopathies in critical care. N Engl J Med. 2014;370(9):847-59.

101. Warkentin TE, Pai M. Shock, acute disseminated intravascular coagulation, and microvascular thrombosis: is 'shock liver' the unrecognized provocateur of ischemic limb necrosis? J Thromb Haemost. 2016;14(2):231-5

102. Delabranche X, Berger A, Boisrame-Helms J, Meziani F. Microparticles and infectious diseases. Med Mal Infect. 2012:42(8):335-43.

103. Meziani F, Delabranche X, Asfar P, Toti F. Bench-to-bedside review: circulating microparticles_-a new player in sepsis? Crit Care. 2010;14(5):236.

104. Reid VL, Webster NR. Role of microparticles in sepsis. Br J Anaesth. 2012:109(4):503-13

105. Okajima K, Uchiba M, Murakami K, Okabe H, Takatsuki K. Plasma levels of soluble E-selectin in patients with disseminated intravascular coagulation. Am J Hematol. 1997;54(3):219-24.

106. Koyama K, Madoiwa S, Nunomiya S, et al. Combination of thrombinantithrombin complex, plasminogen activator inhibitor-1, and protein C activity for early identification of severe coagulopathy in initial phase of sepsis: a prospective observational study. Crit Care. 2014;18(1):R13.
107. Rossi E, Sanz-Rodriguez F, Eleno N, et al. Endothelial endoglin is involved in inflammation: role in leukocyte adhesion and transmigration. Blood. 2012;16:16

108. Rossi E, Smadja DM, Boscolo E, et al. Endoglin regulates mural cell adhesion in the circulatory system. Cell Mol Life Sci. 2016;73(8):1715-39.

109. Ramma W, Ahmed A. Is inflammation the cause of pre-eclampsia? Biochem Soc Trans. 2011:39(6):1619-27.

110. Delabranche X, Quenot JP, Lavigne T, et al. Early detection of disseminated intravascular coagulation during septic shock: a multicentre prospective study. Crit Care Med. 2016;17:17.

111. Guitton C, Gerard N, Sebille V, et al. Early rise in circulating endothelial protein $\mathrm{C}$ receptor correlates with poor outcome in severe sepsis. Intensive Care Med. 2011;37(6):950-6.

112. Perez-Casal M, Downey C, Fukudome K, Marx G, Toh CH. Activated protein $C$ induces the release of microparticle-associated endothelial protein C receptor. Blood. 2005;105(4):1515-22.

113. Perez-Casal M, Thompson V, Downey C, et al. The clinical and functional relevance of microparticles induced by activated protein $\mathrm{C}$ treatment in sepsis. Crit Care. 2011;15(4):R195.

114. Osterud B. Tissue factor expression in blood cells. Thromb Res. 2010;125(1):10

115. Stakos DA, Kambas K, Konstantinidis T, et al. Expression of functional tissue factor by neutrophil extracellular traps in culprit artery of acute myocardial infarction. Eur Heart J. 2015;36(22):1405-14.

116. Gould TJ, Lysov Z, Liaw PC. Extracellular DNA and histones: double-edged swords in immunothrombosis. JJ Thromb Haemost. 2015;13(Suppl 1):S82-91.

117. Delabranche $X$, Stiel L, Severac F, et al. Evidence of netosis in septic shock-induced disseminated intravascular coagulation. Shock. 2017:47(3):313-7.

118. Stiel L, Delabranche X, Galoisy AC, et al. Neutrophil fluorescence: a new indicator of cell activation during septic shock-induced disseminated intravascular coagulation. Crit Care Med. 2016:44(11):e1132-6.

119. Lesesve JF, Martin M, Banasiak C, et al. Schistocytes in disseminated intravascular coagulation. Int J Lab Hematol. 2014;36(4):439-43.

120. Pfitzner SA, Dempfle CE, Matsuda M, Heene DL. Fibrin detected in plasma of patients with disseminated intravascular coagulation by fibrin-specific antibodies consists primarily of high molecular weight factor XIIla-crosslinked and plasmin-modified complexes partially containing fibrinopeptide A. Thromb Haemost. 1997;78(3):1069-78.

121. Cauchie P, Cauchie C, Boudjeltia KZ, et al. Diagnosis and prognosis of overt disseminated intravascular coagulation in a general hospitalmeaning of the ISTH score system, fibrin monomers, and lipoprotein-Creactive protein complex formation. Am J Hematol. 2006;81 (6):414-9.

122. Dickneite G, Czech J, Keuper H. Formation of fibrin monomers in experimental disseminated intravascular coagulation and its inhibition by recombinant hirudin. Circ Shock. 1994;42(4):183-9.

123. Gris JC, Faillie JL, Cochery-Nouvellon E, Lissalde-Lavigne G, Lefrant JY. ISTH overt disseminated intravascular coagulation score in patients with septic shock: automated immunoturbidimetric soluble fibrin assay vs. D-dimer assay. J Thromb Haemost. 2011;9(6):1252-5.

124. Gris JC, Bouvier S, Cochery-Nouvellon E, Faillie JL, Lissalde-Lavigne $G$, Lefrant JY. Fibrin-related markers in patients with septic shock: individual comparison of D-dimers and fibrin monomers impacts on prognosis. Thromb Haemost. 2011:106(6):1228-30.

125. Greenberg CS, Devine DV, McCrae KM. Measurement of plasma fibrin D-dimer levels with the use of a monoclonal antibody coupled to latex beads. Am J Clin Pathol. 1987;87(1):94-100.

126. Wilde JT, Kitchen S, Kinsey S, Greaves M, Preston FE. Plasma D-dimer levels and their relationship to serum fibrinogen/fibrin degradation products in hypercoagulable states. Br J Haematol. 1989;71(1):65-70.

127. Carr JM, McKinney M, McDonagh J. Diagnosis of disseminated intravascular coagulation. Role of D-dimer. Am J Clin Pathol. 1989;91 (3):280-7.

128. Boisclair MD, Ireland H, Lane DA. Assessment of hypercoagulable states by measurement of activation fragments and peptides. Blood Rev. 1990:4(1):25-40.

129. Boisclair MD, Lane DA, Wilde JT, Ireland H, Preston FE, Ofosu FA. A comparative evaluation of assays for markers of activated coagulation and/or fibrinolysis: thrombin-antithrombin complex, D-dimer and fibrinogen/fibrin fragment E antigen. Br J Haematol. 1990;74(4):471-9. 
130. Fourrier F, Jourdain M, Tournois A, Caron C, Goudemand J, Chopin C. Coagulation inhibitor substitution during sepsis. Intensive Care Med. 1995;21(2):S264-8.

131. Fourrier F, Chopin C, Goudemand J, et al. Septic shock, multiple organ failure, and disseminated intravascular coagulation. Compared patterns of antithrombin III, protein C, and protein S deficiencies. Chest. 1992;101(3):816-23.

132. Gando S, Kameue T, Matsuda N, Hayakawa M, Hoshino H, Kato H. Serial changes in neutrophil-endothelial activation markers during the course of sepsis associated with disseminated intravascular coagulation. Thromb Res. 2005;116(2):91-100.

133. Hans GA, Besser MW. The place of viscoelastic testing in clinical practice. Br J Haematol. 2016;173(1):37-48.

134. Brenner T, Schmidt K, Delang M, et al. Viscoelastic and aggregometric point-of-care testing in patients with septic shock-cross-links between inflammation and haemostasis. Acta Anaesthesiol Scand. 2012;56(10):1277-90.

135. Abraham E, Reinhart K, Opal S, et al. Efficacy and safety of tifacogin (recombinant tissue factor pathway inhibitor) in severe sepsis: a randomized controlled trial. JAMA. 2003;290(2):238-47.

136. Warren BL, Eid A, Singer P, et al. Caring for the critically ill patient. Highdose antithrombin III in severe sepsis: a randomized controlled trial. JAMA. 2001;286(15):1869-78.

137. Ranieri VM, Thompson BT, Barie PS, et al. Drotrecogin alfa (activated) in adults with septic shock. N Engl J Med. 2012;366(22):2055-64.

138. Meziani F, Vincent JL, Gando S. Should all patients with sepsis receive anticoagulation? Yes. Intensive Care Med. 2017;43:452-4.

139. van der Poll T, Opal SM. Should all septic patients be given systemic anticoagulation? No. Intensive Care Med. 2017:43(3):455-7.

140. Kenne E, Renne T. Factor XII: a drug target for safe interference with thrombosis and inflammation. Drug Discov Today. 2014;19(9):1459-64.

141. Chen Z, Seiffert D, Hawes B. Inhibition of Factor XI activity as a promising antithrombotic strategy. Drug Discov Today. 2014;19(9):1435-9.

142. Labberton L, Kenne E, Renne T. New agents for thromboprotection. A role for factor XII and XIla inhibition. Hamostaseologie. 2015;35(4):338-50.

143. Caliezi C, Zeerleder S, Redondo M, et al. C1-inhibitor in patients with severe sepsis and septic shock: beneficial effect on renal dysfunction. Crit Care Med. 2002;30(8):1722-8.

144. Zeerleder S, Caliezi C, van Mierlo G, et al. Administration of C1 inhibitor reduces neutrophil activation in patients with sepsis. Clin Diag Lab Immunol. 2003:10(4):529-35.

145. Igonin AA, Protsenko DN, Galstyan GM, et al. C1-esterase inhibitor infusion increases survival rates for patients with sepsis. Crit Care Med. 2012;40(3):770-7.

146. Barratt-Due A, Johansen HT, Sokolov A, et al. The role of bradykinin and the effect of the bradykinin receptor antagonist icatibant in porcine sepsis. Shock. 2011;36(5):517-23.

147. Pixley RA, De La Cadena R, Page JD, et al. The contact system contributes to hypotension but not disseminated intravascular coagulation in lethal bacteremia. In vivo use of a monoclonal anti-factor XII antibody to block contact activation in baboons. J Clin Invest. 1993;91 (1):61-8.

148. Worm M, Kohler EC, Panda R, et al. The factor Xlla blocking antibody 3F7: a safe anticoagulant with anti-inflammatory activities. Ann Transl Med. 2015:3(17):2305-5839.

149. Tucker El, Verbout NG, Leung PY, et al. Inhibition of factor XI activation attenuates inflammation and coagulopathy while improving the survival of mouse polymicrobial sepsis. Blood. 2012;119(20):4762-8.
150. Stroo I, Zeerleder S, Ding C, et al. Coagulation factor XI improves host defence during murine pneumonia-derived sepsis independent of factor XII activation. Thromb Haemost. 2017;117(8):1601-14.

151. Nakamura M, Takeuchi T, Kawahara T, et al. Simultaneous targeting of CD14 and factor Xla by a fusion protein consisting of an anti-CD14 antibody and the modified second domain of bikunin improves survival in rabbit sepsis models. Eur J Pharmacol. 2017:802:60-8.

152. Thiery-Antier N, Binquet C, Vinault S, et al. Is thrombocytopenia an early prognostic marker in septic shock? Crit Care Med. 2016:44(4):764-72.

153. Tsirigotis $P$, Chondropoulos S, Frantzeskaki F, et al. Thrombocytopenia in critically ill patients with severe sepsis/septic shock: prognostic value and association with a distinct serum cytokine profile. J Crit Care. 2016:32:9-15

154. Falcone M, Russo A, Farcomeni A, et al. Septic shock from communityonset pneumonia: is there a role for aspirin plus macrolides combination? Intensive Care Med. 2016:42(2):301-2.

155. Falcone M, Russo A, Cangemi R, et al. Lower mortality rate in elderly patients with community-onset pneumonia on treatment with aspirin. J Am Heart Assoc. 2015;4(1):e001595.

156. Valerio-Rojas JC, Jaffer IJ, Kor DJ, Gajic O, Cartin-Ceba R. Outcomes of severe sepsis and septic shock patients on chronic antiplatelet treatment: a historical cohort study. Crit Care Res Pract. 2013;2013:782573.

157. Smith SA, Choi SH, Collins JN, Travers RJ, Cooley BC, Morrissey JH. Inhibition of polyphosphate as a novel strategy for preventing thrombosis and inflammation. Blood. 2012;120(26):5103-10.

158. Travers RJ, Shenoi RA, Kalathottukaren MT, Kizhakkedathu JN, Morrissey $\mathrm{JH}$. Nontoxic polyphosphate inhibitors reduce thrombosis while sparing hemostasis. Blood. 2014;124(22):3183-90.

159. Heemskerk S, Masereeuw R, Moesker O, et al. Alkaline phosphatase treatment improves renal function in severe sepsis or septic shock patients. Critical care medicine. 2009;37(2):417-23.

160. Pickkers P, Heemskerk S, Schouten J, et al. Alkaline phosphatase for treatment of sepsis-induced acute kidney injury: a prospective randomized double-blind placebo-controlled trial. Crit Care. 2012;16(1):R14.

161. Su F, Brands R, Wang Z, et al. Beneficial effects of alkaline phosphatase in septic shock. Crit Care Med. 2006;34(8):2182-7.

162. Tunjungputri RN, Peters $E$, van der Ven A, de Groot PG, de Mast $Q$, Pickkers P. Human recombinant alkaline phosphatase inhibits ex vivo platelet activation in humans. Thromb Haemost. 2016;116(6):1111-21.

163. Lee S, Ku SK, Bae JS. Anti-inflammatory effects of dabrafenib on polyphosphate-mediated vascular disruption. Chem Biol Interact. 2016;256:266-73.

164. Brill A, Fuchs TA, Savchenko AS, et al. Neutrophil extracellular traps promote deep vein thrombosis in mice. Journal of thrombosis and haemostasis: JTH. 2012;10(1):136-44.

165. Mai SH, Khan M, Dwivedi DJ, et al. Delayed but not early treatment with DNase reduces organ damage and improves outcome in a murine model of sepsis. Shock. 2015;44(2):166-72.

166. McDonald B, Davis RP, Kim SJ, et al. Platelets and neutrophil extracellular traps collaborate to promote intravascular coagulation during sepsis in mice. Blood. 2017:129(10):1357-67.

167. Laukova L, Konecna B, Babickova J, et al. Exogenous deoxyribonuclease has a protective effect in a mouse model of sepsis. Biomed Pharmacother. 2017;93:8-16.

168. Chrysanthopoulou A, Kambas K, Stakos D, et al. Interferon lambda1/ IL-29 and inorganic polyphosphate are novel regulators of neutrophildriven thromboinflammation. J Pathol. 2017;243(1):111-22. 